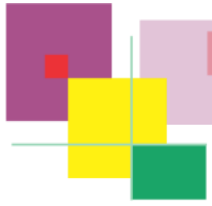

DOI: $10.20396 /$ lil.v24i47.8660243

\title{
Thomas Young, o conceito de "indo-europeu" e a legitimação da Linguística
}

\section{Thomas Young, the concept of "indo-european" and the legitimation process of Linguistics}

\section{Márcio Renato Guimarães*}

\author{
UFPR
}

Resumo: A contribuição do polímata inglês Thomas Young é analisada para além da introdução do termo indo-europeu, como parte do processo de legitimação que antecede a institucionalização da linguística como disciplina acadêmica no século XIX.

Palavras-chave: Indo-europeu, Thomas Young, Institucionalização da Linguística.

Abstract: The contribution of the english polymath Thomas Young is analyzed beyond the introduction of the term indo-european, as part of the legitimation process that precedes the institutionalization of Linguistics as an academic discipline in the XIX century.

Keywords: Indo-european, Thomas Young, Institutionalization of Linguistics.

Em 1813, em uma resenha sobre o Mithridates, de Johann Christoph Adelung (1732-1806), o polímata inglês Thomas Young (1773-1829) utilizou pela primeira vez o termo indo-europeu ${ }^{1}$ para designar uma: 
ancient and extensive class of languages, united by a greater number of resemblances that can well be altogether accidental $[\ldots]$ comprehending the Indian, the West Asiatic, and almost all the European languages (YOUNG, 1813, p. 255).

A resenha foi publicada na icônica e influente Quarterly Review, um bastião do conservadorismo britânico ao longo de boa parte do início do século XIX, famosa e temida por suas resenhas críticas, e especialmente pelo julgamento feito aos poetas da geração romântica inglesa, como Keats, Shelley e Byron (WHEATLEY, 2007, p. 19). As resenhas cobriam uma variedade bastante ampla de obras, literárias ou não, representando o igualmente amplo interesse do público a que se endereçava. Thomas Young (1773-1829), cognominado por seu biógrafo (ROBINSON, 2007) "o último homem que sabia tudo", era médico de profissão, formado em Göttingen, e tinha uma gama bastante ampla de interesses, predominantemente em ciências naturais, sendo mais conhecido por sua teoria sobre a natureza da luz como onda.

O termo indo-europeu (na forma indisch-europäisch) será utilizado por Franz Bopp no prefácio da primeira edição da Vergleichende Grammatik (BOPP, 1833, p. V) e vai continuar sendo empregado em seus textos posteriores, apesar da preferência geral na Alemanha por Indogermanisch. A preferência por indo-europeu por aquele que é entendido como o primeiro linguista de facto (MORPURGO-DAVIES, 1998, p. 14-15) e o fundador do método histórico-comparativo é o que leva, segundo Koerner (1989, p. 152), esse termo a se impor sobre as denominações concorrentes, como indo-germânico, indo-céltico, jafético, ariano, "sankritisch", etc.

O surgimento de termos para designar a "classe", ou "família" de línguas, como talvez preferíssemos denominar, demonstra, na historiografia da linguística, um marcador de importantes mudanças cognitivas (e, obviamente, também sociais) no clima intelectual, que marcam o início da linguística como disciplina institucionalizada. Koerner (1989) observa que, tanto nas ciências naturais como nas sociais, invenções e descobertas frequentemente precedem o termo usado para se referir a elas, e que a linguística não é exceção: 
Although it maybe important to note when and where a particular coinage was first introduced into the technical terminology-indeed, such coinages may signal the inception of or a particular turning point in the professionalization of a field - we should not be surprised to discover that the concept of a particular observation antedates the descriptive term (KOERNER, 1989, p. 150-151).

A partir de uma leitura descuidada da noção de que "o conceito antecede o termo", poderíamos entender que esse conceito se apresenta totalmente acabado e construído no momento em que surge uma cunhagem para ele, derivado de um fato consumado (i.e. a "descoberta" da existência de uma família de línguas indo-europeias), o que certamente não é o caso. Koerner afirma com razão que, no momento em que o termo indo-europeu surge, elementos bastante importantes do que viria a ser o conceito de "indo-europeu" - o qual subjaz ao trabalho da linguística histórico-comparativa - já estarão firmemente estabelecidos (ainda que, como veremos, alguns tenham sido desenvolvidos posteriormente). No entanto, o autor não aprofunda (e nem é esse o seu objetivo) o quanto desse conceito já está presente à época de Young, o quanto será desenvolvimento posterior. Para além da contribuição específica da cunhagem do termo indo-europeu, Thomas Young foi o primeiro a discutir o modelo de classificação de línguas. Muito embora essa discussão tenha aparecido mais tarde e desvinculada de qualquer citação ao trabalho de Young, ela recupera, como veremos, alguns elementos já adiantados por ele, como o caráter "reticulado" e o abandono das scalae hierárquicas. Uma de nossas tarefas no presente artigo será a de desvelar a narrativa subjacente ao conceito de "indo-europeu" distinguindo os dois passos cognitivos nele embutidos. Adicionalmente, apresentaremos as questões subsumidas à discussão de Young dos modelos de classificação passíveis de serem aplicados às famílias linguísticas.

A circunstância de esse termo surgir numa resenha do Mithridates, de Adelung, o último representante da "velha linguística, para Benfey" (1869, p. 272), e ter sido utilizado por Franz Bopp, o primeiro (junto com os irmãos Schlegels) lídimo representante da "nova linguística" histórico-comparada, segundo o mesmo Benfey, coloca essa cunhagem 
em específico no centro do turning point de Koerner. Isso leva ao último ponto de nossa análise que é o de situar a contribuição de Young (e, indiretamente, também a de Adelung) no contexto de mudança cognitiva que antecede e desencadeia o surgimento da linguística como "campo profissionalizado", no dizer de Koerner. Nesse empreendimento de prover essa mudança cognitiva de uma descrição historiográfica mais adequada, não faremos uso do aparato teórico de Konrad Koerner, mas do da socióloga da ciência polono-americana Olga Amsterdamska. Consoante a metodologia dessa autora, situaremos a contribuição de Young no contexto de legitimação da problemática que subjaz o empreendimento de análise históricocomparada que caracteriza a "nova linguística", mas não meramente como um empreendimento intelectual, mas também uma atividade de produção de conhecimento socialmente constituída e regulada no âmbito da instituição universitária.

Na primeira seção, apresentaremos a resenha e a obra resenhada, a fim de estabelecer os subsídios das análises posteriores. A identificação dos passos cognitivos subsumidos ao conceito de "indo-europeu" será objeto da segunda seção, ao passo que na terceira apresentaremos a discussão dos sistemas de classificação presente na obra de Thomas Young. Finalmente, na terceira seção, procederemos ao trabalho de situar a contribuição de Young ao contexto de legitimação que antecede imediatamente o processo de institucionalização da linguística como ciência academicamente constituída.

\section{O Mithridates e a resenha}

O Mithridates, de Adelung, foi publicado em três volumes: o primeiro, em 1806; o segundo, em 1809; e o terceiro dividido em dois tomos, publicados em 1812 e 1817 . Trata-se de uma enciclopédia das línguas e povos do mundo, divididas por regiões geográficas, contendo breves descrições sobre as línguas e os povos que as falavam, listas de palavras e traduções do Pai Nosso como exemplo de texto. Adelung morreu durante os trabalhos de montagem do primeiro volume, que foram concluídos por Johann Severin Vater (1771-1826), descrito nas folhas de rosto da obra como "professor de teologia e bibliotecário em Königsberg", cuja função não excedeu a organização dos escritos de 
Adelung, fazendo pequeníssimos acréscimos ao texto sobre as línguas germânicas (ADELUNG, 1809, p. iv).

A obra emula uma série de escritos com a mesma estrutura, publicados a partir do século XVI e que tinham como base a obra homônima, de 1555, de autoria do polímata suíço, Konrad Gessner (1516-1565). Obras como o Mithridatessão bastante comuns nos séculos XVII e XVIII e pareiam com outros levantamentos sistemáticos da variedade do universo vivo, o que não nos faz estranhar Gessner ser também autor de monumentais historiae de animais e plantas (FISCHER, 1966, p. 270). Essa sanha de levantamentos exaustivos da variedade do mundo, um empreendimento cultural que Hans Fischer chama de Bibliotheca Naturalis, é o resultado do acúmulo, em diversos países europeus, dos materiais, culturais ou físicos, resultantes das expansões comercial e colonial europeias a partir do final do século XV (FISCHER, 1966, p. 272). Ao mesmo tempo, o Mithridates funciona como um importante terminus ad quem: segundo Morpurgo-Davies (1998, p. 40), até a primeira edição de Les Langues du Monde, de Meillet e Cohen, em 1924, nenhuma outra tentativa de cobrir um conjunto tão amplo de línguas seria feita, a não ser pelos Grundriss der Sprachwissenschaft, de Friedrich Müller, publicado em 1876.

Adelung ainda é tributário da narrativa bíblica sobre a origem das línguas, empenhando-se em descobrir, através das pistas dadas pelo Texto Sagrado, a região do mundo em que se situava o Paraíso terrestre, o berço da humanidade, que o autor situava na Caxemira (ADELUNG, 1806, p. 17). Ao mesmo tempo, defendia uma origem única para todas as línguas humanas, de acordo com o estabelecido no Pentateuco (Ibid., p. XI).

Apesar de familiarizado com os escritos de Sir William Jones, ao qual cita oito vezes no primeiro volume, seis das quais na descrição do Sânscrito (Ibid., p. 134-175), não dá a mínima mostra de conhecer a teoria de Jones do parentesco entre o sânscrito e as línguas da Europa. A noção de parentesco entre línguas não lhe é estranha: diz que os termos mais necessários das línguas (como os termos para "cabeça", "pé" e nomes de animais domésticos) são os que mais revelam se elas são aparentadas (verwandt), mas acredita que não são os termos em si, e sim as raízes, que revelam esse parentesco (Ibid., p. vii). Dessa forma, os vocábulos precisam ser decompostos para que os elementos sejam revelados, o que demanda um conhecimento da estrutura de cada 
língua. Ele utiliza 55 vezes no primeiro volume (ADELUNG, 1806) o termo semítico, em curso desde que Schlözer o introduziu, em 1781. Não utiliza, no entanto, o termo jafético, utilizado pelo mesmo Schlözer.

O primeiro volume (ADELUNG, 1806) apresenta as línguas da Ásia, que ele divide em duas grandes classes: monossilábicas (Einsylbische) e polissilábicas; essas últimas, classifica de acordo com a região do continente: Oeste, Central Superior (Hohes Mittel), Sibéria, Sul da Ásia e Ilhas do Sul. No segundo volume (Idem, 1809), dedicado às línguas da Europa, a classificação segue as famílias divididas tradicionalmente: Cantábrica (basco), Céltica, Germânica, Eslava, Lética (ou Germano-eslava), romano-eslava (ou valáquia, incluindo o romeno), Chúdica (línguas fino-úgricas) e duas línguas "mistas", o húngaro e o albanês. No entanto, para além da distinção entre línguas mono e polissilábicas, nenhum outro critério de classificação que não fosse o geográfico (e o reconhecimento das "famílias" tradicionais, para as línguas europeias) é apresentado ou discutido. Antes, Adelung se resguarda de discutir o assunto, alegando não ter nenhuma Lieblingsmeinung, nenhuma tese a defender a qualquer custo a respeito da relação entre línguas (1806, p. III-IV).

A resenha de Thomas Young foi publicada logo após a publicação do primeiro tomo do terceiro volume (ADELUNG, 1812), a que faz referência. $\mathrm{O}$ segundo tomo só seria publicado cinco anos mais tarde (ADELUNG, 1817). Não é a única incursão de Young no campo das linguagens e talvez não seja a mais influente: à parte de escrever o verbete "Languages", de 33 mil palavras, para a Encyclopaedia Britannica, ele desempenhou um papel importantíssimo na decifração dos hieróglifos egípcios, cabendo-lhe a primazia de uma série de descobertas importantes que, posteriormente, não apenas facilitaram, como pode-se dizer que possibilitaram a decifração da escrita por Champollion. A recusa do francês em reconhecer a primazia de Young foi encampada por todo o campo subsequente da Egiptologia e qualquer reconhecimento da sua contribuição foi, durante décadas, encarada como uma tentativa de denegrir a imagem de Champollion como o "gênio solitário" fundador da disciplina (ROBINSON, 2007, p. 210211).

Young começa sua resenha apresentando um extenso levantamento de obras semelhantes à de Adelung, desde o homônimo de Gessner, até 
as coleções de composição semelhante publicadas por Megiser, Duret, Chamberlayne, Hervas, Marcel e Pallas (YOUNG, 1813, p. 250-252). Em seguida, detém-se ao problema da natureza da classificação das línguas e das dificuldades em rastrear parentescos mais amplos (YOUNG, 1813, p. 252-254). Para Young, se a mera presença, em duas línguas diferentes, de formas semelhantes com um mesmo ou similar significado for tomada como prova suficiente (sic) de parentesco, então mais de metade das línguas do mundo vão exibir traços de uma tal conexão. Muito embora algumas conexões, como a presença de uma vogal A e de uma consoante labial na palavra para "pai", na maior parte das línguas da Terra, possam estar ligadas a uma onomatopeia, seria mais difícil de explicar tal origem para a presença da sequência NM na palavra para "nome". De qualquer forma, mesmo nesses casos, a distribuição dessas formas semelhantes não é absoluta. Esses étimos universalmente recorrentes são muito poucos e não são suficientes para rastrear o parentesco entre todas as línguas e uma mesma origem comum, e tentar estabelecer um "etymologicon universale" seria um empreendimento de visionário.

Young considera muito estreitos os critérios de Adelung, entendendo que ele considera línguas diferentes formas muito próximas de uma mesma língua. Para Young (1813, p. 254), essa distinção deveria se embasar antes em diferenças mais substantivas e, dessa forma, reduz as 362 línguas reconhecidas por Adelung nos volumes já publicados a cerca de 200, estimando o número máximo de línguas no mundo em 500.

Ao comentar a situação da origem da humanidade por Adelung no Himalaia, Young relaciona a língua do Tibet às demais do Leste da Ásia (Ibid., p. 255), constituindo a classe das línguas monossilábicas, que ele concorda com Adelung ao considerar a mais antiga das classes de línguas existentes, distintas das demais línguas da terra pela circunstância de representarem diferenças de significado por tons. Para além dessa classe, segundo Young, só pode ser reconhecida claramente a classe das línguas indo-europeias, cuja origem situa ao sul e a oeste dessa região original.

Na sequência, ele apresenta o esquema geral da classificação das línguas da terra (Ibid., p. 256-263) e da p. 263 até o final do texto ele faz uma cuidadosa (re)apresentação (merecedora, talvez, da mesma qualificação de "tediosa" que ele faz da apresentação do próprio 
Adelung) dos grupos e das famílias linguísticas constantes nos tomos já publicados, justificando ponto a ponto as suas divergências da classificação de Adelung.

$\mathrm{Na}$ sua classificação, Young divide as línguas da terra em três grandes grupos: monossilábicas (que ele mantém de Adelung), indoeuropeias (incluindo o cantábrico e o semítico de Adelung) e as tatáricas, subdivididas em cinco subclasses: esporádicas (finlandês, húngaro, albanês), caucásicas (incluindo também o armênio e o osseta), tartárica, siberiana e insular. Apesar de incluir o árabe no esquema geral das línguas do mundo, ao tratar do assunto (Ibid., p. 267) vai dizer que a família árabe (Arabian) não está intimamente ligada às línguas europeias, apesar de ter tido alguma influência do latim e do grego e apresentar alguns supostos étimos em comum com as línguas indoeuropeias. Afirma (Ibid., p. 285), ainda, ser possível, uma conexão do armênio com o sânscrito e o persa. Do albanês, que situa nas "línguas esporádicas", diz ser uma mistura de "grego, latim, germânico, eslavo ou turco", havendo uma parte que não se relacionada com nenhuma outra língua (Ibid., p. 284-285).

A resenha de Young se situa na normalidade no que diz respeito a alguns grandes debates: ele já dá mostras de migrar da grande pergunta do século XVIII, a respeito da origem da linguagem, para o debate do século XIX, sobre o reconhecimento de famílias linguísticas. Dá mostras do desencanto dos grandes esquemas de classificação universal e das tentativas de reconhecer étimos que minimamente recuem até a Protolíngua. Duas famílias podem ser facilmente reconhecidas: a monossilábica e a indo-europeia; nos casos restantes, ele se limita a rastrear correspondências parciais.

Young retoma essa discussão no verbete Languages, que escreveu para a Encyclopaedia Britannica em 1824, e que aparece reproduzido em Young (1855). Apesar de esse artigo ser maciçamente uma reprodução da resenha de 1813 (que ele cita referindo-se em terceira pessoa ao "Dr. Young"), ele repercute críticas a algumas ideias contidas na resenha, revendo a noção de que línguas monossilábicas representam um tipo mais antigo de língua, porque monossílabos não são necessariamente formas básicas que se aglutinam para compor as formas mais complexas. Ao contrário, formas mais curtas podem ser abreviações de formas mais longas mais antigas, como blame de blaspheme (Ibid., p. 484). Ao mesmo tempo, ele dá as probabilidades 
de uma língua apresentar palavras idênticas com o mesmo significado e um étimo comum: continuam sendo insignificantes se forem apenas uma palavra; são três contra uma, no caso de duas palavras; para três palavras sobem para dez contra uma; seis palavras dariam 1.700 chances contra uma, e oito, 100.000 contra um (Ibid., p. 481). Seria tentador ligar esse tipo de raciocínio aos cálculos estatísticos utilizados pelos linguistas da escola greenbergiana para embasar os seus argumentos. No entanto, não parece haver nenhum tipo de ligação histórica e o uso desse tipo de raciocínio ao longo do século XIX, se aconteceu, não apresenta nenhum registro digno de nota. De fato, em um texto que justifica e aplica métodos estatísticos (muito mais sofisticados do que os de Young) para justificar parentesco de longo termo com base em étimos identificados em famílias linguísticas muito diferentes, Bengtson e Ruhlen atribuem a Alfredo Trombetti, no início do século XX, a ideia de utilizar-se tais métodos (BENGTSON \& RUHLEN, 1994, p. 281).

Em um nível mais imediato, podemos reconhecer os trabalhos de Adelung e Young como representantes do interesse do público letrado da Europa do início dos mil e oitocentos para a questão da origem das línguas modernas. Ambos os autores anunciam a centralidade dessa questão no decorrer do século XIX, em detrimento da discussão da origem da linguagem, que já começa a dar sinais de exaustão. Ao mesmo tempo, eles são mais tributários do passado que se encerra do que arautos do futuro que começa.

\section{Da História das Línguas e dos Modelos de Parentesco}

Em Young, ainda mais do que em Adelung, está presente de maneira bastante clara os elementos da explicação do pertencimento das línguas indo-europeias a uma mesma família linguística e da origem dessa família a partir da dispersão (por migração dos falantes) da parent language, da língua ancestral. Essa explicação pode ser dividida em dois passos cognitivos que guardam, entre si, uma simetria reflexiva no que diz respeito à relação passado-presente:

\section{Teoria da Família Linguística}

A existência de um determinado componente de palavras semelhantes com significado semelhante em duas ou mais línguas 
leva à suposição de que as referidas línguas descendem de uma mesma língua original e, portanto, pertencem a uma mesma família linguística.

\section{Teoria da Dispersão}

Uma língua, levada por seus falantes a uma região mais ampla do que a região em que originalmente era falada, com o passar do tempo e com o isolamento entre cada região em que passa a ser falada, modifica-se em línguas diferentes.

A teoria da família linguística parte do presente e remonta ao passado. A teoria da dispersão parte do passado e explica como se originou o estado de coisas existentes, mas não implica necessariamente (e essa ausência de implicação se verifica tanto em Adelung quanto em Young) no próximo passo, que é o da reconstrução do estado de coisas passado, significando isso tanto a reconstrução da língua-mãe quanto das circunstâncias da sua dispersão e de seu isolamento.

Do ponto de vista do timing cognitivo, a identificação de uma família linguística deveria vir antes da suposição de que uma dispersão ocorreu no passado, e talvez com algumas famílias linguísticas isso tenha acontecido. De um ponto de vista histórico, ou melhor, historiográfico (e poderíamos dizer igualmente menos ingênuo), os fatos mostram um panorama mais complexo, pelo menos no que diz respeito à identificação da família indo-europeia. Lembremos que essa identificação já aparece em vários autores antes de Young (ou mesmo do famoso parágrafo de Sir William Jones), podendo remontar à hipótese de Saumaise e Boxhorn, da primeira metade do século XVII, de que a língua dos citas é a fonte da maior parte das línguas europeias e do persa antigo, como faz o próprio Koerner (1989, p. 151), ou até cem anos antes disso, no trabalho do orientalista suíço Theodor Biblianter (1509-1564), como faz Metcalf (2013).

Apenas para remontarmos ao que parece ser o evento mais antigo de identificação de família linguística na vida intelectual do Ocidente europeu, quando Dante Alighieri identifica as formas vulgares derivadas do latim em sua De Vulgari Eloquentia, não se pode dizer que o pertencimento das línguas românicas à sua família deriva de um exercício comparativo. A história toda dessa família linguística é de conhecimento geral na Europa do fim da Idade Média. Os dois passos 
cognitivos representados acima aparecem como teoria, quando outros casos de semelhança entre línguas são explicados por um raciocínio indutivo de analogia com a relação entre as línguas românicas e o latim, como vai acontecer depois na formulação da chamada "hipótese cítica". Porém, o conhecimento da circunstância histórica da formação das línguas românicas revela a prevalência mais ou menos tácita da ideia da origem por dispersão desde o início do processo. Metcalf (2013, p. 22) identifica outro elemento importante da equação: a noção de uma história universal comum para toda a humanidade, providenciada pela tradição hebraico-cristã. Nesse sentido, o elemento subjacente à teoria da dispersão é a história bíblica: a dispersão após a descida da Arca, mais precisamente, após o episódio da Torre de Babel.

Nem Adelung nem Young parecem se interessar pela origem da linguagem em si, e muito menos considerar seriamente algum tipo de hipótese monogenética para todas as línguas da terra. Antes, existe a ênfase (maior em Young do que em Adelung) na dificuldade no empreendimento de rastrearem-se parentescos muito remotos no tempo e uma tendência tácita à investigação dos parentescos mais solidamente estabelecidos em dados comparativos. Essa ausência de uma reflexão mais "filosófica" sobre a origem da linguagem e a adoção de uma abordagem mais "histórica", baseada em algum tipo de comparação, tem sido apontado como uma tendência de pensamento que vai desembocar no historicismo essencial da nova linguística, a linguística do século XIX (p. ex., MORPURGO-DAVIS, 1998, p. 34-37). Em Adelung e Young, no entanto, não se pode pensar nisso como uma reação historicista à discussão setecentista da origem da linguagem. Adelung, por sua interpretação estritamente bíblica dos fatos, e até pela escolha do formato de Bibliotheca Naturalis, é mais um vestígio de um passado moribundo (que, aliás, se encerra com ele), do que um precursor da modernidade. Young agrega elementos interessantes à equação, discutindo critérios probabilísticos para rastrear as chances da semelhança entre duas formas linguísticas ser fortuita e, como veremos na próxima seção, discutindo a própria noção de classificação. Mas, mesmo nesses dois pontos, as reflexões de Young representam um dead end na linha da continuidade de discussões que ocorrem no âmbito dos estudos da linguagem, no sentido em que a sua discussão não é retomada por nenhum autor relevante na nova ciência da linguística, que está em vias de se institucionalizar. A tradição de discussão sobre 
os modelos de classificação das línguas, desde o modelo da Stammbaumtheorie, de Schleicher, passando pela Wellentheorie, de Schuchardt e Schmidt, até as modernas versões do equilíbrio pontuado, tem outro pedigree.

Um elemento adicional, que diz respeito à noção de história que pode ser deduzida do trabalho tanto de Adelung quanto de Young: ambos ainda estão sujeitos à ênfase do século XVIII de utilizar a história para explicar o estado de coisas presentes. A ênfase que Aarslef (1982, p. 161) reconhece no trabalho das disciplinas históricas do século XIX, a da reconstrução do passado, ainda não se instalou.

\section{Dos Sistemas de Classificação}

Assim como acontece com a discussão feita por Young, no seu verbete para a Encyclopaedia Britannica, sobre o uso do cálculo de probabilidades como critério para verificar o parentesco entre línguas, também sua discussão sobre a natureza do sistema de classificação utilizado para as línguas antecipa uma discussão posterior, mas, ao mesmo tempo, não se pode dizer que ela tenha interferido diretamente no desenvolvimento dos sistemas de classificação adotados pelo linguistas posteriores (como Schleicher, por exemplo). Nos dois casos, trata-se de questões já presentes no "clima de opinião" da época. No caso do sistema de classificação, como veremos, a discussão sobre sua natureza não se faz e a adoção de um sistema predominantemente cladístico é tácita pela comparação implícita das línguas com seres vivos (ou, melhor dizendo, com espécies de seres vivos). Já na segunda página da resenha, Young $(1813$, p. 252) coloca a sua preferência por um sistema natural:

A perfect natural order of arrangement, in treating of the peculiarities of different languages, ought to be regulated by their descent from each other and their historical relations; a perfect artificial order ought to bring together into the same classes all those genera which have any essential resemblances, that is, such as are not fortuitous, nor adoptive, nor imitative or derived from onomatopoeia. 
A base do sistema natural - a descendência, isto é, o fato de uma classe de línguas derivar de uma mesma língua ancestral - já está solidamente reconhecida. Observe que artificial, no contexto acima, deve ser traduzido por "adequadamente elaborado", e não se opõe a natural: uma classificação natural adequadamente elaborada deve incluir em uma mesma classe apenas os gêneros que não apresentam, entre suas formas, semelhanças fortuitas, advindas de empréstimo lexical, nem derivada de imitação de sons ou onomatopeias. Ou seja, aqueles cujas semelhanças revelam formas derivadas historicamente de uma mesma forma ancestral.

Do ponto de vista dos sistemas naturais de classificação, a próxima questão é a opção entre os sistemas naturais e os sistemas ordenados, ou hierárquicos:

It has been observed by Linné, that the order of nature is reticulated, while that of art passes on in a single line; and still more strictly speaking, the order of nature may be compared to a solid, which has three dimensions, and which could not be adequately represented even by a map, or a reticulated structure (YOUNG, 1813, p. 252).

$\mathrm{Na}$ moderna cladística, são reticulados aqueles cladogramas que incluem, além das relações "verticais" de parentesco, relações "horizontais" decorrentes de processos de hibridização, relevantes no surgimento de espécies novas (SOUZA e LORENZI, 2008, p. 24). À época de Young, eram entendidas como reticuladas aquelas classificações que se opunham às classificações hierárquicas (ou filosóficas, como eram chamadas), como a de Lineu, em que os seres vivos eram arranjados em escalas lineares escalonadas do mais simples para o mais complexo. A base dessa classificação hierárquica, ou scala naturae, era o chamado "princípio de plenitude" (Sapp, 2009, p. 11), baseado na ideia platônica de que todos os fenômenos materiais são representações imperfeitas do mundo fixo das ideias verdadeiras. Nesse caso, não haveria lacunas no mundo material; tudo o que pode existir há de existir em algum lugar e pode ser alinhado em uma escala do mais simples ao mais complexo, ou, antes, do mais imperfeito ao que mais se aproxima do modelo perfeito no mundo das ideias. 
Em Young (1845, p. 571), ao discutir modelos de classificações de animais e plantas, ele prefere a classificação de Lineu à de Jussieu, apesar de ela ser mais natural, e exatamente por isso mesmo: ele vê a classificação de Jussieu como inadequada,

since its author has sacrificed all logical and systematical laws to the attempt to follow nature, in analogies, which are often discoverable only with great difficulty, and which are seldom reducible to methodical definitions (Young, 1845, p. 571).

Jussieu e, principalmente, Lamarck iniciaram o movimento de reação às classificações platônicas, este último reinterpretando a scala naturae como a organização dos seres vivos de acordo com sua posição na escala evolutiva. No entanto, a graduação entre os seres só seria perceptível nos grupos principais da série geral, mas não em espécies ou mesmo em gêneros. As condições ambientais em que as espécies de animais e plantas vivem não têm relação direta com o aumento na complexidade de sua organização, e muitas vezes produzem anomalias ou desvios na forma externa e nas características que não podem ser atribuídas somente ao incremento na complexidade de organização (SAPP, 2009, p. 11).

Na sistemática biológica as classificações estritamente filogenéticas não foram entendidas sempre como melhores do que as classificações "hierárquicas", ao menos até o início da "revolução filogenética", no último quartel do século XX (ERESHEFSKY, 2004, p. 94-126). Na Linguística, como já revelam as passagens de Young (1813, p. 252), a escolha foi sempre pelos modelos exclusivamente baseados em parentesco sobre os sistemas lógicos ou lineares, ainda que de maneira tácita e com um debate não tão amplo ou central como na Biologia.

A única proposta comparável à da scala naturae, por seu platonismo implícito, é a distinção entre línguas orgânicas e línguas aglutinativas, apresentada por Friedrich Schlegel na sua Über die Sprache und Wiesheit der Indier. Para Schlegel, línguas orgânicas como o sânscrito são sistemas superiores de expressão do pensamento, refletindo a superioridade espiritual do passado, quando a humanidade estava mais próxima de sua origem divina. A partir daí, iniciou-se um lento processo 
de degeneração, com a erosão dessa organicidade original, em direção à aglutinação. As línguas descendentes do sânscrito - na concepção de Schlegel, todas as línguas indo-europeias - refletiam esse processo de degeneração, tornando-se cada vez mais "mecânicas", em um processo de regressão de um vigor original, intelectual e espiritual, em direção a uma mentalidade grosseira e materialista.

Essa concepção será abandonada por Franz Bopp, o fundador do método histórico-comparativo, que vai embasar a pesquisa na disciplina institucionalizada da linguística. Em primeiro lugar, Bopp abandona a ideia de que o sânscrito é a língua-mãe de onde descendem todas as línguas indo-europeias, situando-a como uma das irmãs. Em segundo lugar, ele desmonta o argumento de que o sânscrito é uma língua orgânica, ao questionar a associação feita por Schlegel de organicidade com processos flexivos. Ao estabelecer que os únicos processos que podem ser legitimamente chamados de flexivos são as alterações no interior das raízes por mudanças de vogais, Bopp observa que eles são muito pouco comuns em línguas como as indo-europeias, mesmo o sânscrito, onde predominam os processos de composição, e mais comuns e sistemáticos em línguas semíticas como o árabe (BOPP, 1820, p. 11-12).

É possível entrever na discreta preferência pelos sistemas naturais de classificação das línguas uma tendência intelectual importante da época de Young, que acabará se realizando nas classificações predominantes da linguística a partir dessa época, até hoje. O sistema de árvore adotado por Schleicher é estritamente natural, nos termos de Young. Os sistemas hierárquicos, de base platônica, não só foram totalmente abandonados, como já no século XIX se apresentou uma forte tendência a não entender a mudança linguística como um processo de degeneração. Com a Wellentheorie, de Schuchardt e Schmidt, podemos entrever a admissão de parentescos horizontais por cruzamento, e, ao mesmo tempo, o parentesco vertical, por descendência. Mas, como no caso do uso das probabilidades, não existe uma linha de descendência intelectual nítida entre Young e as propostas da linguística, sendo mais fruto de tendências intelectuais difusas ao tempo de Young, cuja ligação, se é que existe, com esses desenvolvimentos posteriores não está clara.

De qualquer forma, ao mesmo tempo que Young reflete essas tendências difusas que não têm continuidade imediata, ele marca o 
momento imediatamente anterior à "virada cognitiva" representada pela publicação do Conjugationssystem, de Bopp. Primeiro, pelo fato da resenha de Adelung, por Young, ser uma espécie de "acerto de contas" final com a "velha linguística" de Benfey, representada pela tradição dos Mithridates. E, por fim, mas não menos importante, por ter sido um dos últimos diletantes a dar contribuições importantes no campo da Linguística. A obra de Bopp e, principalmente, sua carreira como professor universitário, marca a exata deflagração do processo de institucionalização da Linguística. Como se não bastasse, também no que diz respeito à Egiptologia, podemos traçar o mesmo paralelo entre o polímata diletante Thomas Young e o especialista acadêmico Champollion.

\section{Conclusão: Institucionalização e Legitimação}

Ao introduzir o estudo do contexto intelectual imediatamente anterior ao surgimento da primeira escola de conhecimento da linguística institucionalizada, a socióloga da ciência Olga Amsterdamska observa que, no período anterior ao surgimento de um novo campo de estudos, a análise do ambiente intelectual se revela particularmente importante

New fields of study do not emerge in an intellectual vacuum, and broad intellectual trends appear to play a particularly crucial role in the early stages of the formation of a discipline, prior to its institutionalization. It is during such early stages when the autonomy of the field is not yet assured and its boundaries are being negotiated that external legitimation must be most actively sought (AMSTERDAMSKA, 1988, p. 34).

Nesse sentido, os textos de Thomas Young revelam esse contexto externo mais amplo, não só porque uma nova teoria ou metodologia está para emergir, mas porque a própria disciplina institucionalizada da linguística está para emergir. Ou seja, trata-se do surgimento de um novo contexto social de produção do conhecimento, de uma nova carreira acadêmica. Nesse sentido, Young revela o contexto imediatamente anterior ao surgimento da linguística, tanto do ponto de 
vista intelectual quanto social. Ele é um dos últimos não-especialistas a dizerem coisas relevantes historicamente a respeito do assunto ${ }^{3}$. A partir de Franz Bopp, a historiografia da linguística só vai levar em consideração a produção acadêmica da linguística institucionalizada, feita na Universidade, por professores universitários.

O formato da produção de Young, que foi levada em consideração aqui, também revela muito tanto do contexto intelectual quanto do contexto social em que foi produzida e, principalmente, marca o contraste com a produção subsequente na linguística institucionalizada. Esse formato é ditado não só pela característica de diletante nãoespecialista e não-acadêmico do autor, mas também pelo público a que se pretende atingir: um público igualmente não-acadêmico, instruído o suficiente para acompanhar as questões levantadas pelo autor, curioso o suficiente sobre o assunto para se interessar por ele e formado predominantemente por pessoas da mesma extração social de Young: as classes superiores instruídas europeias - burguesia ou nobreza, mas cada vez mais a primeira, principalmente profissionais com alguma formação acadêmica (médicos, como Thomas Young, juristas, como Friedrich Schlegel), mas não especialistas no assunto.

O contraste com o formato do texto de Adelung é igualmente revelador. Adelung é o último representante não só de um determinado tipo de autor diletante, como Young, mas o seu Mithridates, sendo o último de uma série (e, coincidentemente, batizado com o nome do primeiro da série), também representa o término da relevância histórica do formato Mithridates. A resenha de Young, por outro lado, representa perfeitamente a transição para os formatos posteriores, acadêmicos, como os textos de Franz Bopp, do ponto de vista de pelo menos dois aspectos. Em primeiro lugar, do ponto de vista do gênero textual próprio da divulgação científica na nova ciência, transitando do formato de artigo em revistas de debate intelectual mais amplo para o formato do artigo em periódico especializado. Em segundo lugar, como vimos nas seções anteriores, no sentido de introduzir uma discussão mais sofisticada sobre o modelo de classificação das línguas e dos critérios para se determinar se duas ou mais línguas são aparentadas.

O público da nova ciência institucionalizada também é diferente do público a que se dirigiam os Mithridates e as resenhas de periódicos generalistas e polímatas como o Quarterly Review. Trata-se de um público em um certo sentido mais "autofágico", igualmente formado 
por acadêmicos e especialistas que produzem os novos formatos relacionados à ciência institucionalizada.

Por fim, algumas descontinuidades importantes que apontamos nas seções anteriores entre os textos de Young analisados aqui e a produção posterior são reveladores de que o processo de legitimação do novo campo de estudos, a que se refere Amsterdamska no trecho acima, concluiu-se com a própria formação do campo de estudos. Como vimos anteriormente, a produção linguística posterior não cuidou das questões relacionadas ao parentesco entre as línguas indo-europeias, às teorias sobre a localização da Urheimat da língua-mãe, e as migrações do povo ou povos que a falavam e a dispersaram pela Eurásia. A discussão dos modelos de classificação só será retomada mais tarde, nos termos da nova disciplina e no timing ditado pelas discussões institucionalizadas.

Uma vez legitimado o campo de estudos, perde relevância histórica para a nova disciplina o debate com um público mais amplo, que passa a ser, a partir da institucionalização, "externo" à disciplina. O debate acerca da localização da Urheimat e das migrações vai continuar principalmente fora da Linguística, em áreas como a Antropologia e em outras que o conhecimento acadêmico institucionaliza, mas também em um público mais amplo. Esse envolvimento de um público não específico nas discussões sobre as origens indo-europeias vai ser particularmente importante na difusão da assim chamada "narrativa ariana", a qual terá desenvolvimentos importantes para muito além da Linguística e de qualquer outra discussão acadêmica ${ }^{4}$. Nesse ponto, no entanto, ultrapassamos em muito Thomas Young e os propósitos iniciais deste artigo.

\section{Referências bibliográficas}

AARSLEF. From Locke to Saussure. Essays on the study of language and intellectual history. London: Athlone Press. 1982.

ADELUNG, J. C. Mithridates oder allgemeine Sprachkunde. Erste Theil. Berlin: Vossische Buchhandlung. 1806.

ADELUNG, J. C. Mithridates oder allgemeine Sprachkunde. Zweite Theil. Berlin: Vossische Buchhandlung. 1809.

ADELUNG, J. C. Mithridates oder allgemeine Sprachkunde. Dritte Theil. Erste Abtheilung. Berlin: Vossische Buchhandlung. 1812.

ADELUNG, J. C. Mithridates oder allgemeine Sprachkunde. Dritte Theil. Zweite Abtheilung. Berlin: Vossische Buchhandlung. 1817 
AMSTERDAMSKA, O. Schools of thought: the development of linguistics from Bopp to Saussure. Dordrecht: D. Reidel. 1987

BENFEY, T. Geschichte der Sprachwissenschaft. München: Gottaschend Buchhandlung. 1869.

BENGTSON, J. D.; RUHLEN, M. Global etymologies. In: RUHLEN, M. (ed.) The origin of languages: studies in linguistic taxonony. Stanford: Stanford University Press, p. 277-336. 1994.

BOPP, F. Analytical comparison of the Sanskrit, Grek, Latin, and Teutonic Languages, shewing the original identity of their grammatical structure. In: Annals of Oriental Literature, v. 1, n.1, p. 1-60. 1820. BOPP, F. Vergleichende grammatik des Sanskrit, Zend, Griechischen, Lateinischen, Litthauischen, Gothischen und Deutschen. Berlin: Drückerei der Königl. Akademie der Wissenschaften. 1833.

WHEATLEY, K. Plotting the success of the Quaterly Review. In: CUTMORE, J. (ed.) Conservatism and the Quaterly Review. London: Pickering \& Chatto, p. 19-40. 2007.

ERESHEFSKY, M. The poverty of the Linnaean hierachy. Cambridge: Cambridge University Press. 2004.

FISCHER, H. Conrad Gessner (1516-1565) as Bibliographer and Encyclopedist. In: The Library, v. 4, p. 269-281. 1966.

GESNER, K. Mithridates: de differentiis linguarum tum ueterum tum quæ hodie apud diuersas nationes in totu orbe terrarum in usu sunt. Zurich: Froschauer. 1555.

GUIMARÃES, M. R. O termo ariano e a narrativa indo-europeia. Línguas e Letras, v. 19, n. 43, p. 40-58. 2018.

KOERNER, E. F. K. Observations on the sources, transmission, and meaning of Indo-european and related terms in the development of linguistics. In: KOERNER, E. F. K. Practicing linguistic historiography: selected essays. Amsterdam/Philadelphia: John Benjamins, p. 149-177. 1989.

METCALF, G. J. On language diversity and relationship from Bibliander to Adelung. Amsterdam/Philadelphia: John Benjamins. 2013.

MORPURGO-DAVIES, A. Nineteenth-Century linguistics. London: Longman. 1998.

ROBINSON, A. The last man who knew everything. Oxford: Oneworld. 2007. 
SAPP, J. The new foundations of evolution. Oxford: Oxford University Press. 2009.

SOUZA, V. C.; LORENZI, H. Botânica sistemática. Nova Odessa: Plantarum. 2008.

YOUNG, T. "Mithridates oder allgemeine sprachkunde". In: The Quarterly Review, v. 10, p. 250-292. 1813.

YOUNG, T. A course on lectures on natural philosophy and the mechanical arts. 2. ed. London: Taylor and Walton. 1845.

YOUNG, T. "The article 'Languages' from the supplement to the Encyclopaedia Britannica". In: LEITCH, J. (ed.) Miscellaneous works of the late Thomas Young. v.3. London: John Murray, p. 478-559. 1855.

\section{Notas}

* Doutor em Estudos Linguísticos pela Universidade Federal do Paraná (UFPR). Professor Associado da Universidade Federal do Paraná (UFPR).

${ }^{1}$ Utilizamos o termo indo-europeu, e seus equivalentes (jafético, indo-germânico etc.), em português, referind-nos aos equivalentes nas diferentes línguas europeias, a não ser quando se quiser ressaltar uma variante ou uso específico em uma determinada língua.

${ }^{2}$ Ver, a esse respeito, Ereshefsky (2004, p. 94-126).

${ }^{3}$ É claro que esse "historicamente relevante" é sempre, necessariamente, uma escolha historiográfica, feita por quem observa o evento histórico de um ponto de vista também historicamente situado.

${ }^{4}$ Uma história detalhada desse desenvolvimento, tanto na Antropologia como em textos destinados a um público mais amplo e produzidos na periferia das disciplinas institucionalizadas do século XIX, inclusive sob o ponto de vista do surgimento das teorias racialistas, é apresentada em Guimarães (2018). 